\title{
Designing a Boost Inverter to Interface between Photovoltaic System and Power Utilities
}

\author{
Sk. Md. Golam Mostafa ${ }^{1}$ \\ ${ }^{I}$ (Lecturer, International Islamic University Chittagong)
}

\begin{abstract}
The global electrical energy consumption is steadily rising. To meet the growing demand of electricity and reduction of greenhouse gas emission has prompted renewed interest in the renewable energy system. The cost of renewable energy technologies is on a falling trend and is expected to fall further as demand and production increases. Among various possibilities, the solar cell is an instinct source of energy, which is increasingly being studied, researched and for conversion of electrical energy. In this paper we have studied dc to ac conversion technique using boost inverter with solar energy stored via PV cells in a battery as input. In this way we have enabled to convert $12 \mathrm{~V}$ dc to $220 \mathrm{~V}$ ac for home applications. The overall project has been verified by simulation with $\operatorname{OrCAD} 15.7$ simulation software. This technique supports the use of dc-ac boost inverter technique to feasible solution for solar home application.
\end{abstract}

Keywords -Boost Inverter, VSI, Ground Isolation, Lock out circuit.

\section{Introduction}

Solar Cells supply electric energy renewable from primary resources. Solar cells are rarely used individually. Cells with similar characteristics are under peak sunlight $\left(1 \mathrm{~W} / \mathrm{m}^{2}\right)$ the maximum current delivered by a cell is approximately $30 \mathrm{~mA} / \mathrm{cm}^{2}$. Cells are therefore paralleled to obtain the desired current [1]. So, it can charge a battery up to 12 volt DC. For residential use, all equipment requires a pure sinusoidal $220 \mathrm{~V}$ ac power supply. For this a static DC-AC converter is inserted between the solar cells and the distribution network. DC to $\mathrm{AC}$ conversion has been established as one of the most common operations in power electronics. The solar cell transforms the light energy into continuous electric energy. It represents a source with a good energy density. From an electric point of view, the solar cell is considered as a voltage source. This source is nevertheless imperfect. Therefore it is necessary to insert an inverter between the solar cell and the network in order to obtain the alternating electric source, assuming the transfer of light energy to the network. The typical voltage source inverter (VSI) uses the topology, which has a characteristic that the average output voltage is always lower than the input dc voltage [2]. Thus if an output voltage higher than the input one is needed, a boost dc-dc converter must be used between the dc source and inverters. Depending on power and voltage level involved, this solution can result in high volume, weight, and cost and reduce efficiency. The full bridgetopology can however be used as a boost inverter that can greater an output ac voltage higher than the input dc voltage. A traditional design methodology is the use of buck inverter. One of the characteristics of the most classical inverter is that it produces an AC output instantaneous voltage always lower than the dc input voltage. Thus if an output voltage higher than the input one is needed, a boost dc-dc must be used between the dc source and the inverter [3]. This paper also describes a new P.W.M. strategy for a voltage source inverter. This modulation strategy reduces the energy losses and harmonics in the P.W.M. voltage inverter. The technique allows the P.W.M. voltage source inverter to become a new feasible solution for solar home application.

\section{DC - DC Converter}

In many industrial applications, it is required to convert a fixed-voltage dc source into a variablevoltage dc source. A dc-dc converter converts directly from dc to dc and simply known as a dc converter. A dc converter can be considered as dc equivalent of an AC transformer with a continuously variable turn ratio. Like a transformer, it can be used to step down or step up a dc voltage source.

\section{A. The Principle of step up operation}

A converter can be used to step up a dc voltage and an arrangement for step-up operation is shown in Fig 3.1(a). When switch SW is closed for time $t_{1}$, the inductor current rises and energy is stored in inductor $\mathrm{L}$. If the switch is open for time $t_{2}$, the energy stored in the inductor is translated through diode D and inductor current falls. Assuming a continuous current flow, the waveform for the inductor current is shown in Fig1(b).

When converter is turned on, the voltage across the inductor is

$$
v_{l}=\mathrm{L} \frac{d i}{d t}
$$

And this gives the peak-to-peak ripple current in the inductor as 


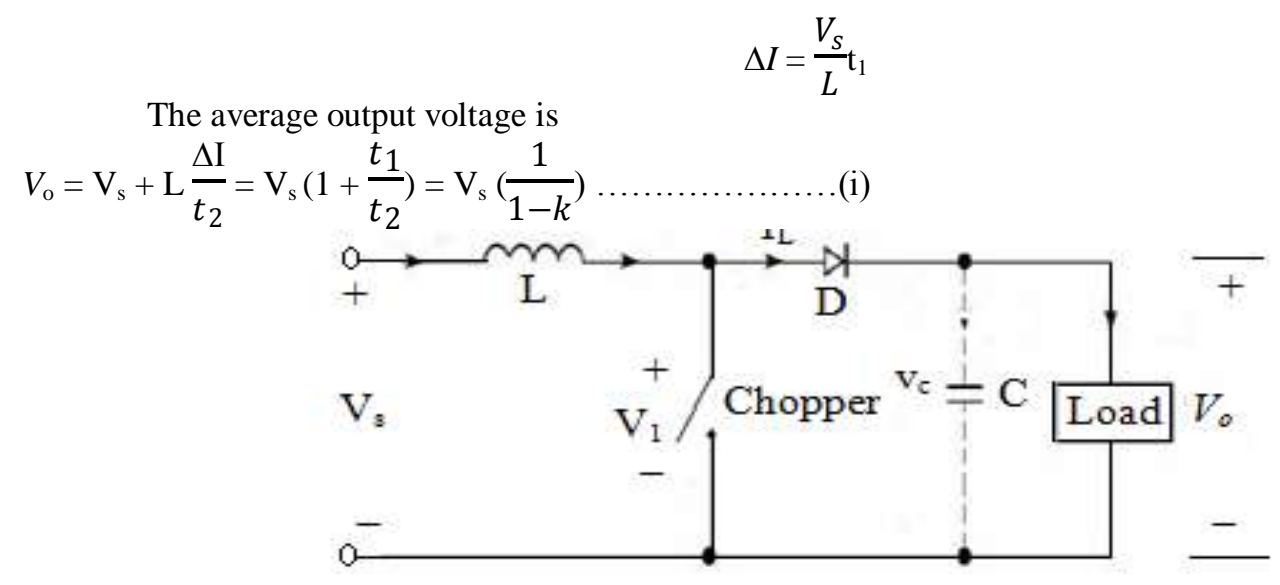

(a) Step-up arrangement

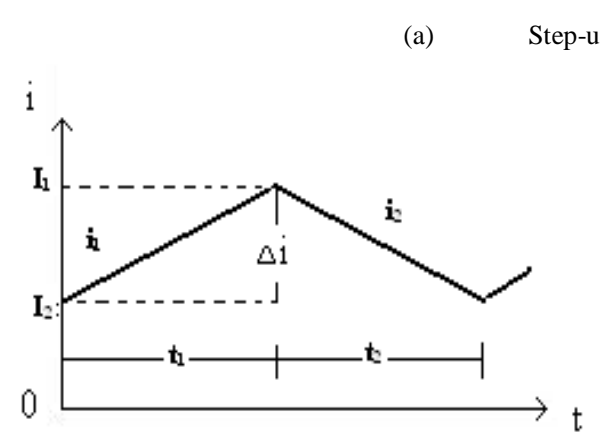

(b) Current waveform

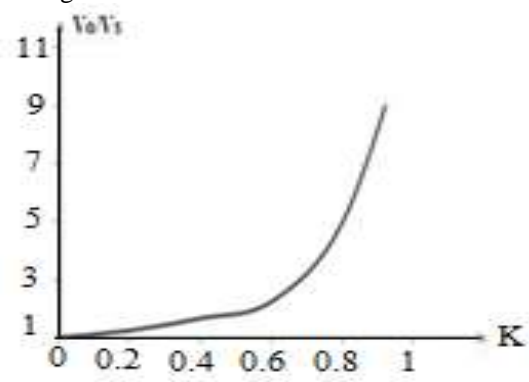

(c) Output Voltage

(b)

Fig1: Arrangement of step-up operation

If a large capacitor $\mathrm{C}$ is connected across the load as shown by dashed lines in Fig1(a), the output voltage is continuous and $v_{\mathrm{o}}$ becomes the average value $\mathrm{V}_{\mathrm{o}}$. we can notice from the Equation (i) that the voltage across the load can be supply by varying the duty cycle $\mathrm{k}$ and the minimum output voltage is $V_{s}$ when $\mathrm{k}=0$. However the converter cannot be switch on continuously such that $\mathrm{k}=1$. For values of $\mathrm{k}$ tending to unity, the output voltage become very large and is very sensitive to change in $\mathrm{k}$, as shown in Fig 1(c).

\section{B. Performance parameter}

The power semiconductor devices require a minimum time to turn on and turn off. Therefore, the duty cycle $\mathrm{k}$ can only be controlled between a minimum value $\mathrm{k}_{\min }$ and a maximum value $\mathrm{k}_{\operatorname{mix}}$, thereby limiting the minimum and maximum value of output voltage. The switching frequency of the converter is also limited. The load ripple current depends inversely on chopping frequency f as $\Delta \mathrm{I}_{\max }=\mathrm{V}_{\mathrm{s}} / 4 \mathrm{fL}$. The frequency should be as high as possible to reduce the load ripple current and to minimize the size of any additional series inductor in the load circuit.

The performance parameters of the step-up and step-down converters are as follows:

$>$ Ripple current of inductor, $\Delta \mathrm{I}_{\mathrm{L}}$;

$>$ Maximum switching frequency, $\mathrm{f}_{\max }$;

$>$ Condition for continuous and discontinuous inductor current;

$>$ Maximum value of inductor to maintain continuous inductor current;

$>$ Ripple content of the output voltage and output current, THD;

$>$ Ripple content of the input current, THD;

\section{Boost Inverter:}

\section{Description Of The Circuit}

The typical single phase VSI uses the topology which has the characteristic that the average output voltage is always lower than the input dc voltage. Thus, if an output voltage higher than the input one is needed, a boost dc-dc converter must be used between the dc source inverter as shown in Fig 2. Depending on the power and voltage levels involved, this solution can result in high volume, weight, cost and reduced efficiency. The full bridge topology can, however, be used as a boost inverter that can generate an output ac voltage than the input dc voltage $[4,5]$. 


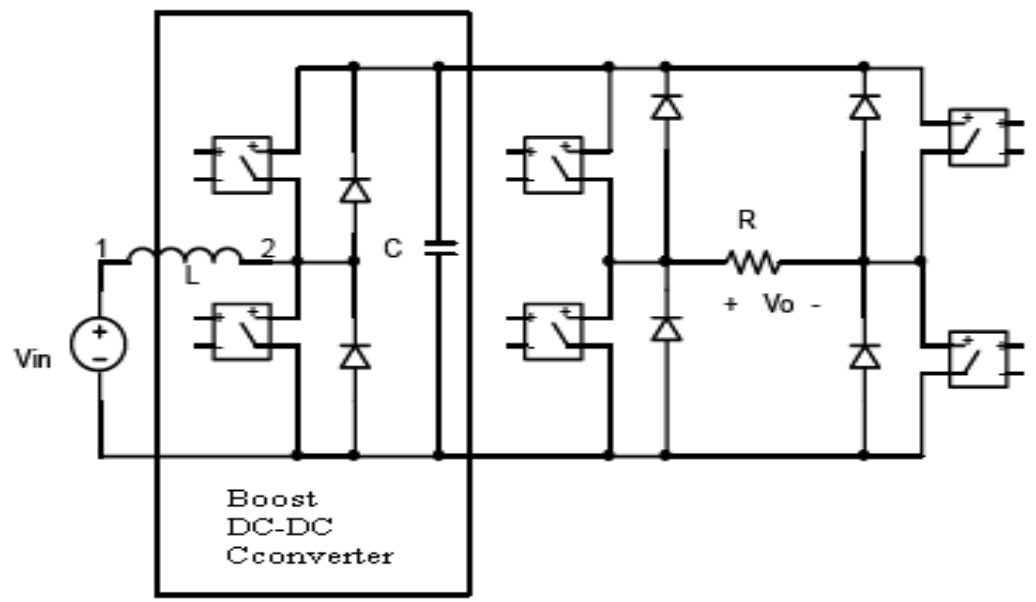

Fig 2: Circuit used to generate an AC voltage larger than DC input voltage.

\section{A. Basic Priciple:}

Let us consider two dc-dc converters feeding a resistive load $\mathrm{R}$ as shown in Fig 3(a).The two converters produces dc-biased sine wave output such that each source only produces a unipolar voltage as shown in Fig 3(b). The modulation of each converter is 180 degrees out of phase with the other so that the voltage excursion across the load is maximized. Thus, the output voltage of the converters are described by

$$
\begin{aligned}
& v_{a}=\mathrm{V}_{\mathrm{dc}}+\mathrm{V}_{\mathrm{m}} \operatorname{Sin} \omega \mathrm{t} . \\
& v_{b}=\mathrm{V}_{\mathrm{dc}}-\mathrm{V}_{\mathrm{m}} \operatorname{Sin} \omega \mathrm{t} .
\end{aligned}
$$

Thus, the output voltage is sinusoidal as given by

$v_{o}=v_{a}-v_{b}=2 \mathrm{~V}_{\mathrm{m}} \operatorname{Sin} \omega \mathrm{t}$

Thus, a dc bias voltage appears at each end of the load with respect to ground, but the differential dc voltage across the load is zero [6].

\section{B. Principle of Boost Inverter:}

Each converter is a current bidirectional boost converter as shown in Fig 3(a). The boost inverter consists of two boost converters as shown in Fig 3(b). The output of the inverter can be controlled by one of the two methods: (1) Use a duty cycle D for converter A and a duty cycle of (1- D) for converter B. (2) Use a differential duty cycle for each converter such that each converter produces a dc-biased sine wave output. The second method is preferred and it uses controllers A and B to make the capacitors voltage $v_{a}$ and $v_{b}$ follow a sinusoidal reference voltage.

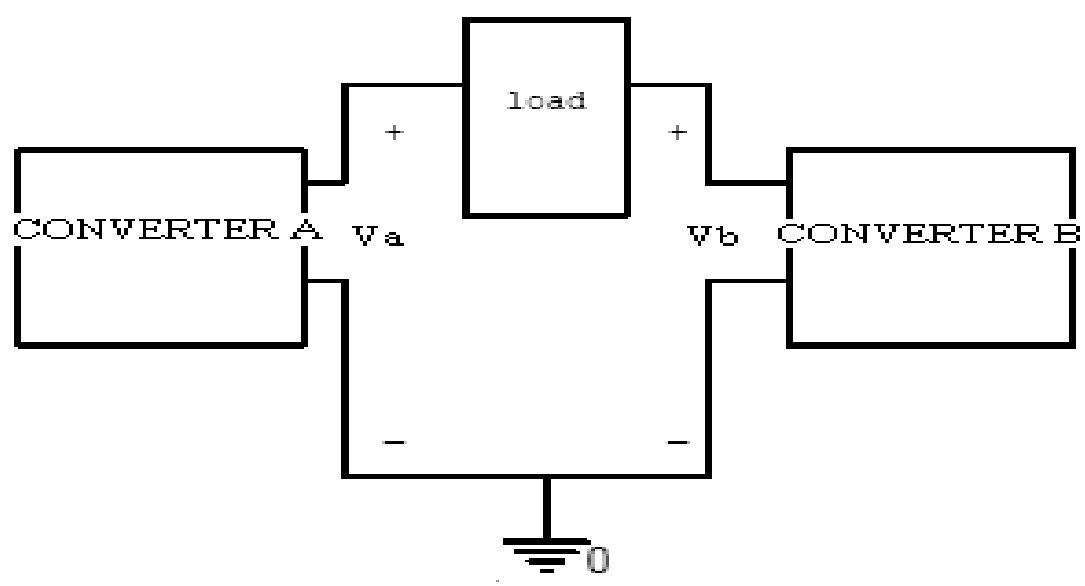

Fig 3 (a) 

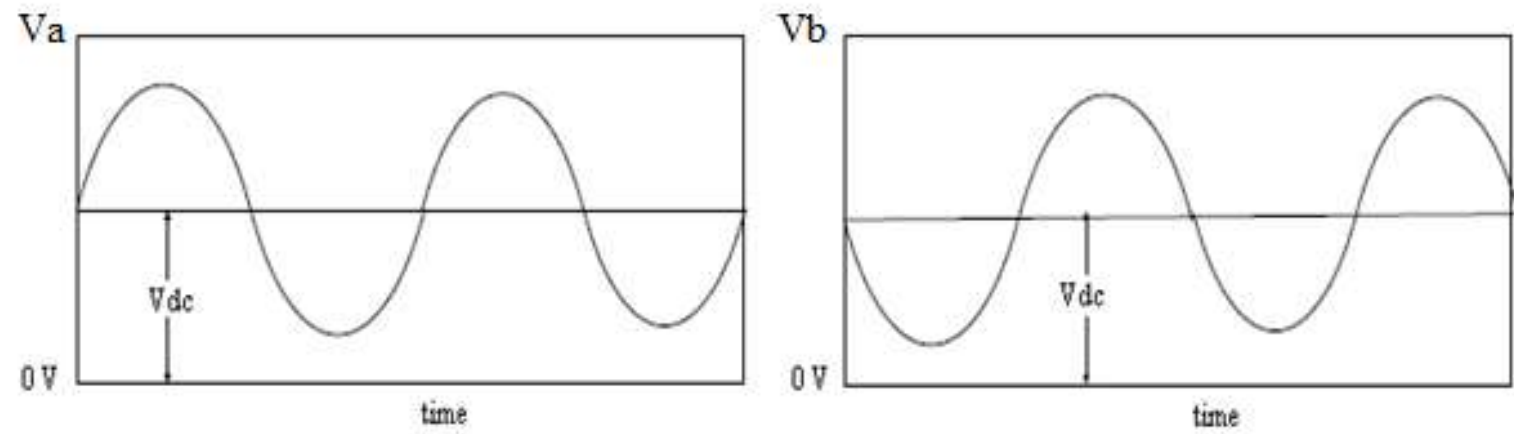

Fig 3 (b)

Fig3: (a) Two dc- dc converter, (b) output voltage

\section{Circuit Simulation And Result}

Fig 5 shows the conversion structure proposed in this paper. It consists of the cascade connection of two stages. The first stage is a boost-regulator and the second stage is the boost inverter.

\section{A. System description:}

The boost dc-ac converter is shown in Fig 5. It includes dc supply voltage $V_{\text {in }}$, input inductors $L_{1}, L_{2}$ and $L_{3}$, power switches $S_{1-} S_{5}$, transfer capacitor $C_{1-} C_{3}$, free-wheeling diode $D_{1-} D_{5}$ and load resistance $R$. The principal purpose of the controllers $A$ and $B$ is to make the capacitor voltages $V_{1}$ and $V_{2}$ follow as as possible a sinusoidal reference.

\section{B. Ground Isolation:}

For switching operation by IGBT a switching pulse have to be provided between the gate and the emitter of the IGBT. In fig 5(d) IGBT S2, emitter is grounded but IGBT S1, emitter is not grounded directly but through the IGBT S2. So the switching pulse which is respect to the normal ground can be supplied to the S2 but not to S1. To supply the pulse to S1 the ground must be isolated from normal ground. This is done by ground isolator circuit.

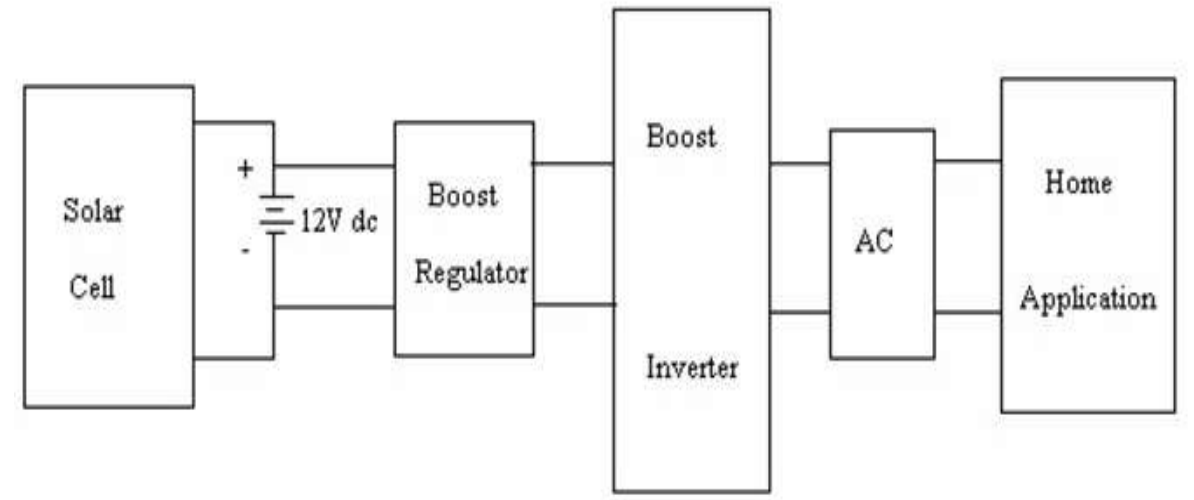

Fig 4: The conversion structure from solar cell to home

\section{Lock out Circuit:}

Theoretically we consider the pulses have no rise time and fall time, but practically they have. When two pulses used those are identical but invert of one another in current bidirectional boost converter where two IGBT are connected serially may cause problems. The pulses are shown in Fig 5(c). At the time when the pulses are rising or falling both of the two IGBTs are on and there will create a short path, so a large current flows through them which can burn the IGBT. The problem is faced by a circuit, lock out circuit. The basic is at the time rising or falling, it is forced to be zero at the switching end. So that the transition period is overcome, then which was rising again and which was falling remains zero. The circuit is shown below.

\section{Simulation And Experimental Result}

The parameters of the circuit for fig 10 are as follows:
$\mathrm{S}_{1}-\mathrm{S}_{5}$
: IRGBC40F (IGBT)
$\mathrm{D}_{1}-\mathrm{D}_{5}$
: MUR850 (diodes)
$\mathrm{C}_{1}-\mathrm{C}_{2}-\mathrm{C}_{3}$
: 400uF 
$\mathrm{L}_{1}-\mathrm{L}_{2}-\mathrm{L}_{3}$ $: 10 \mathrm{mH}$

Frequency, $\mathrm{f}=50 \mathrm{~Hz}$

$\mathrm{R}=200 \mathrm{ohm}$

$\mathrm{V}_{\mathrm{in}}=12 \mathrm{~V}_{\mathrm{dc}}$

$\mathrm{V}_{\text {out }}=220 \mathrm{~V}_{\text {ac }}$ (approximately)

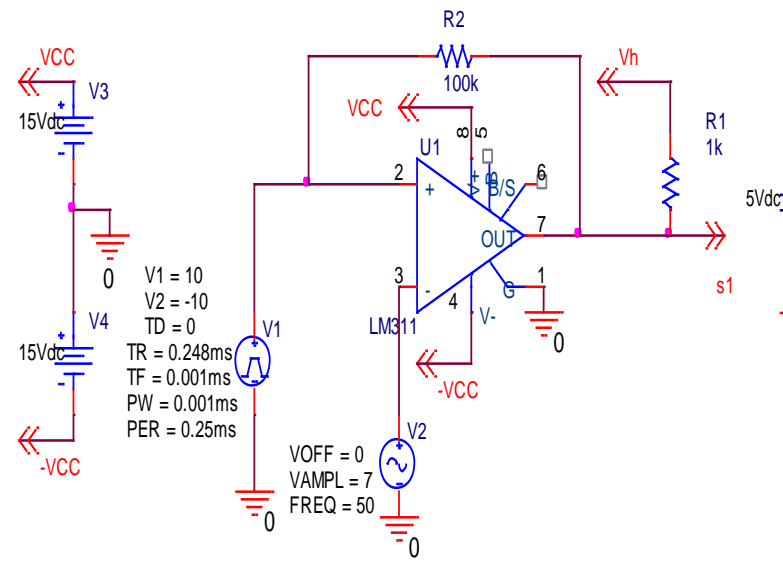

Fig 5 (b)
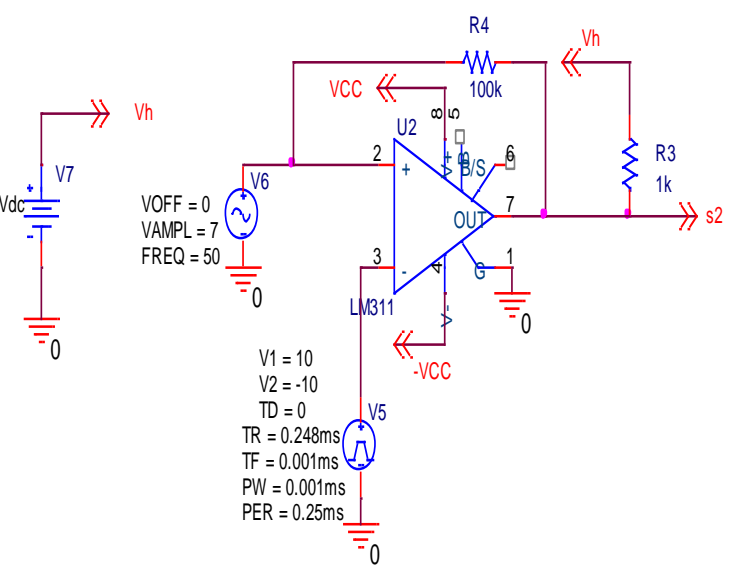

Fig 5 (c)
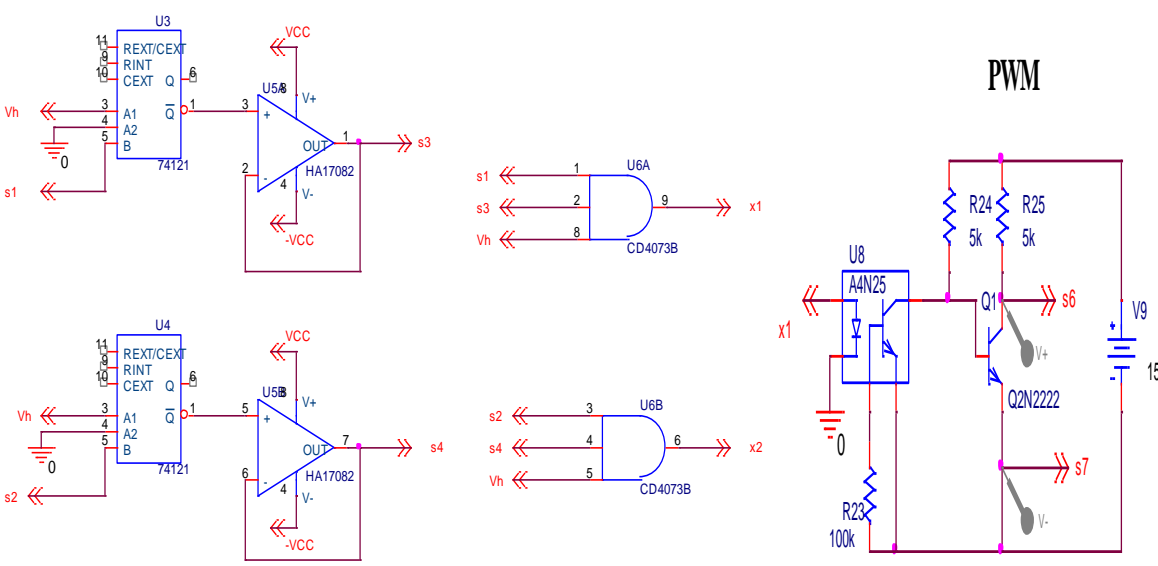

Inverted PWM

Fig 5 (c) Lock out circuit

Fig 5 (d)

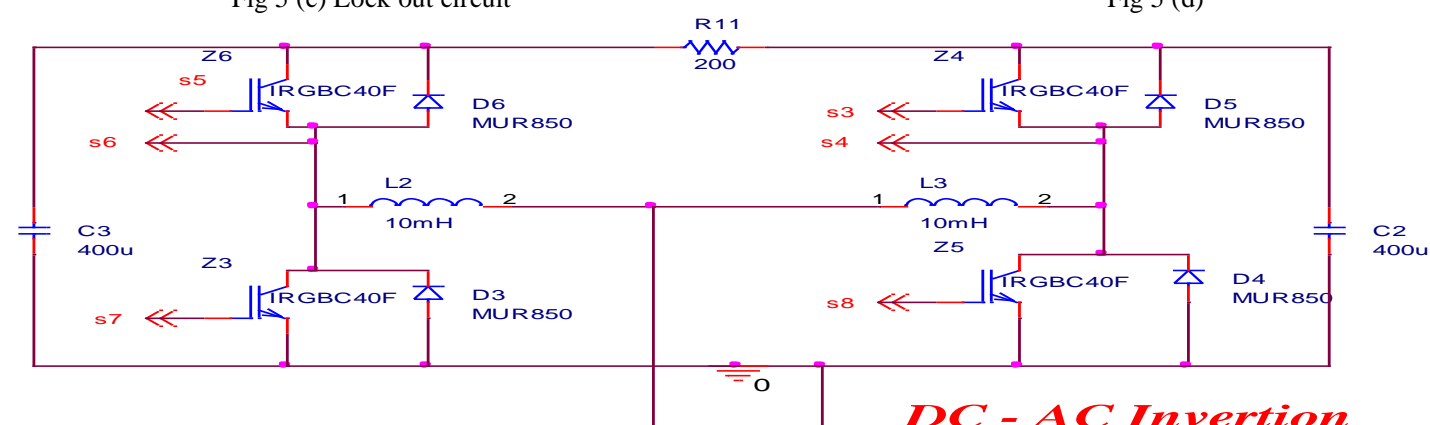
D1

DC - AC Invertion

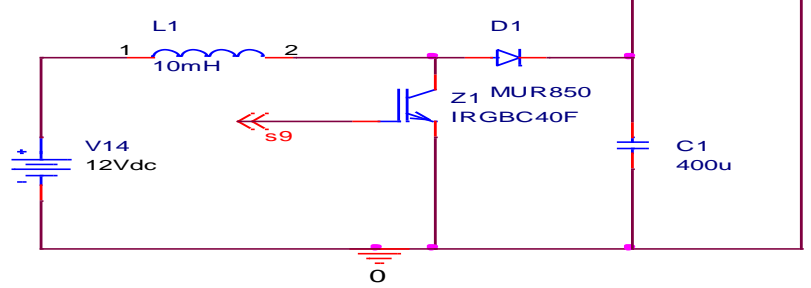

DC - DC Boost

Fig 5 (e) 


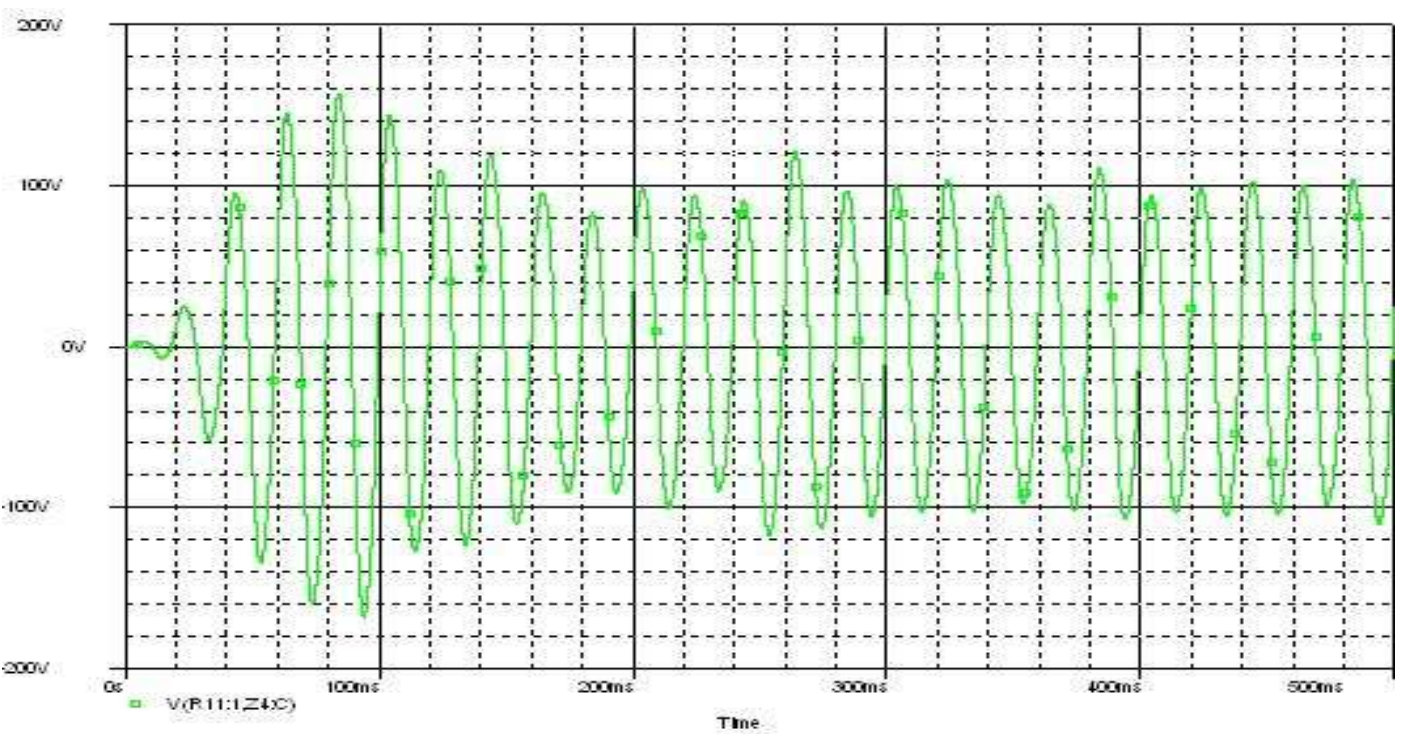

Fig 5 (f)

Fig 5:(a) PWM generation, (b) Inverted PWM generation, (c) Lock out circuit, (d) PWM and inverted PWM with ground isolation, (e) 12V dc to $220 \mathrm{~V} 50 \mathrm{~Hz}$ ac conversion, (f) voltage

\section{Conclusion}

In this paper we tried to implement a new type dc to ac inverter. We use IGBTs as active switches which operate at fixed frequency. Here we use different linear and nonlinear loads. Our simulation result is not completely coping with the proposed theory. Because in ours simulation we used the ideal conception. The new inverter is applicable in solar home application and UPS design when the ac voltage is larger than the dc link voltage is needed, with no need of second power conversion stages. There is a vast scope for future work about this project. Here we use SPWM to control the IGBTs which operate at high frequency and pulse width change automatically. We may use other modulation techniques to obtain the IGBTs gate. At the transistor period of the gate pulses (direct and complementary pulse) we should employ proper lock circuit. We know, at the timing of switching the power is lost as heat. It is possible the output will be smooth and ripple free at lower switching frequency. Then the loss will be decreased and component works more perfectly.

\section{References}

[1] Photovoltaic Panel Simulation User's Guide, Educational Bookmarks, Australian Cooperative Research Centre for Renewable Energy (ACRE), August 14-1998.

[2] C. Cecati, A. Dell' Aquila and M. Liserre , “ Analysis and control of a three-phase dc/ac step-up converter”, in proc. IEEE ISIE'02 Conf., pp. 850-856,July 2002.

[3] RafiaAkhter, AminulHoque, "Analysis of a PWM Boost Inverter for solar home application". CISE 2006, International Conference, Enformatika, Volume 17, ISSN 1305-5315, pp. 212-216, December 2006.

[4] Ram'on O. C'aceres, Ivo Barbi," A Boost DC- AC Converter: Analysis, Design, and Experimentation”, IEEE transactions on power electronics, vol. 14, pp. 134-141, January 1999.

[5] R. C' aceres and I. Barbi, "A boost dc-ac converter: Operation, analysis, control and experimentation", in Proc. Int. Conf. Industrial Electronics, Control and Instrumentation (IECON'95), pp. 546-551, Nov. 1995.

[6] Power Electronics, Circuits, Devices and Applications, third edition, Muhammad H. Rashid. 